\title{
AmpC $\beta$-lactamases in Urinary Klebsiella pneumoniae Isolates: First Report of ACC Type AmpC $\beta$-lactamase Resistance in Iran
}

\author{
Maryam Ghane $^{1^{*} \text { (D) }}$, Laleh Babaeekhou ${ }^{1}$, Mahdi Jafar Shanjani ${ }^{1}$ (D)
}

1. Dept. of Biology, Islamshahr Branch, Islamic Azad University, Islamshahr, Iran

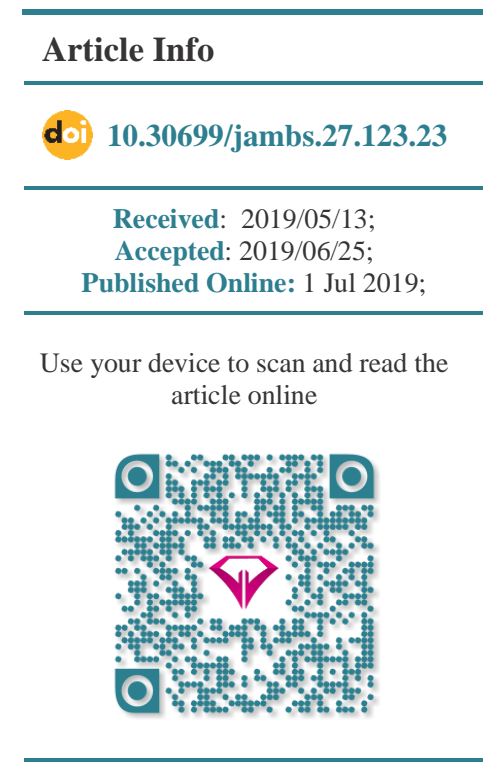

Corresponding Information:

Maryam Ghane, Dept. of Biology,

Islamshahr Branch, Islamic Azad University, Islamshahr, Iran

E-Mail: ghane@iiau.ac.ir

\begin{abstract}
Background \& Objective: The production of plasmid-mediated AmpC betalactamases (PMABLs) among urinary Klebsiella pneumoniae isolates causes a severe problem to the successful treatment of urinary tract infections (UTIs). This study was designed to evaluate antimicrobial resistance, the presence of AmpC beta-lactamase genes, and the genetic relatedness among $K$. pneumoniae strains separated from patients with UTI.
\end{abstract}

Materials \& Methods: In this cross-sectional descriptive study, a total of $100 \mathrm{~K}$. pneumoniae isolates were collected from UTI cases in Milad Hospital, Tehran, Iran. The sensitivity of the isolates to 12 antibiotics was tested using the Kirby-Bauer disk diffusion method. AmpC production was determined using a boronic acid combineddisk test. Polymerase chain reaction (PCR) was carried out to screen all isolates with family-specific PMABL genes. The genetic relatedness of AmpC-producing isolates was determined by an enterobacterial repetitive intergenic consensus polymerase chain reaction (ERIC-PCR).

Results: Over a period of 11 months, PMABLs were detected in 49 isolates (49\%) of $K$. pneumoniae. Resistance to at least three classes of antimicrobials was detected in $30(61.2 \%)$ PMABL producers. Among AmpC producers, 34 isolates harbored only one $A m p C$ gene group, including MOX $(n=11), \operatorname{EBC}(n=8), \operatorname{ACC}(n=7)$, CIT $(\mathrm{n}=4), \operatorname{FOX}(\mathrm{n}=2)$, and DHA $(\mathrm{n}=2)$. Multiple $A m p C$ gene groups were detected in 15 isolates. The ERIC-PCR showed the polyclonal distribution of AmpC-producing isolates.

Conclusion: In our study, a high frequency of AmpC-producing K. pneumoniae was observed. This is the first report of ACC type AmpC beta-lactamase in Iran. Strategies to minimize the spread of $\mathrm{AmpC}$ beta-lactamase-producing isolates should be implemented.

Keywords: Klebsiella pneumoniae, AmpC beta-lactamases, Urinary tract infections

C. Copyright $\odot$ 2019, This is an original open-access article distributed under the terms of the Creative Commons Attribution-noncommercial 4.0 International License which permits
copy and redistribution of the material just in noncommercial usages with proper citation.

\section{Introduction}

Urinary tract infections (UTIs) are a problematic health issue that can cause severe clinical complications and create substantial economic costs (1). Klebsiella pneumoniae is among the most frequently isolated bacteria from UTIs. It is responsible for a significant proportion of hospital-acquired and healthcare-associated infections worldwide (2). In recent decades, the drug resistance of $K$. pneumoniae has rendered the efficacy of beta-lactam antibiotics insufficient (3). The emergence of resistance against beta-lactam drugs due to AmpC cephalosporinases and extended spectrum beta lactamases (ESBLs) is a global public health problem (4).

AmpC beta lactamases are important cephalosporinases whose genes are located on the chromosomes of microorganisms such as Citrobacter spp., Enterobacter spp., Morganella spp., Hafnia spp., Providencia spp., Serratia spp., and Shigella spp. (5).
They are active against penicillins, monobactams, cephalosporins, oxyiminocephalosporins, and cephamycins. These enzymes, unlike ESBLs, are not impeded by clavulanic acid (5).

Plasmid-mediated AmpC cephalosporinases were first identified in 1989 and are thought to be a derivative of chromosomal AmpC genes (6). The presence of such genes in transmissible plasmids facilitates their distribution to the other hospital microorganisms. Plasmid-mediated AmpC beta-lactamases (PMABLs) are most commonly found in nosocomial $K$. pneumoniae and Escherichia coli isolates (7-9), and their presence has been reported in other members of the Enterobacteriaceae family (9). This has increased the spread of PMABLs worldwide (5).

Infections caused by AmpC beta-lactamaseproducing isolates are clinically and epidemiolog- 
ically important and may increase morbidity and mortality $(\mathbf{1 0 , 1 1 )}$.

To the best of our knowledge, few data are available concerning the frequency of PMABLs in urinary $K$. pneumoniae isolates in Iran. Therefore, the main goal of the present study was to assess the frequency of $A m p C$ genes and their variants in urinary $K$. pneumoniae isolates. In addition, the enterobacterial repetitive intergenic consensus polymerase chain reaction (ERIC-PCR) was used to specify the genetic relatedness of AmpC-producing isolates.

\section{Materials and Methods}

\section{Bacterial Isolates}

In this descriptive cross-sectional study, 100 urinary $K$. pneumoniae isolates were obtained from hospitalized patients in Milad Hospital, Tehran, Iran, from December 2016 to October 2017. The isolates were identified as $K$. pneumoniae by colony morphology, gram staining and standard biochemical tests (12). The ethical approval of the present study was provided by the Ethics Committee of Islamic Azad University of Tehran Medical Branch (No: IR.IAU. TMU.REC.1396.278).

\section{Antimicrobial Susceptibility Testing}

All K. pneumoniae isolates were examined for their antibiotic resistance profile using Kirby Bauer's disk diffusion method according to the instructions of the Clinical and Laboratory Standard Institute (CLSI) (13).

The antibiotic disks used were ceftriaxone $(30 \mu \mathrm{g})$, ceftazidime $(30 \mu \mathrm{g})$, cefoxitin $(30 \mu \mathrm{g})$, cefepime $(30$ $\mu \mathrm{g})$, gentamicin $(30 \mu \mathrm{g})$, ciprofloxacin $(30 \mu \mathrm{g})$, levofloxacin $(5 \mu \mathrm{g})$, amikacin $(30 \mu \mathrm{g})$, imipenem $(10$ $\mu \mathrm{g})$, meropenem $(30 \mu \mathrm{g})$, piperacillin $(30 \mu \mathrm{g})$ and aztreonam $(30 \mu \mathrm{g})$ (Mast Diagnostics, UK). E. coli ATCC 25922 was used as a reference (13).

Multidrug resistant (MDR) was estimated according to previously described definitions (14).

\section{Screening of AmpC beta-lactamase-producing Strains}

All the isolates were tested for AmpC beta-lactamase production using discs of cefoxitin $(30 \mu \mathrm{g})$ alone and in combination with boronic acid $(400 \mu \mathrm{g})$. For this purpose, each isolate was inoculated on a MuellerHinton agar plate (Himedia, India). The discs were then placed on the surface of the plate and incubated overnight at $37^{\circ} \mathrm{C}$. An increase of $\geq 5 \mathrm{~mm}$ in zone diameter around the cefoxitin disc in combination with boronic acid compare to that of cefoxitin disc alone was considered positive (15).

\section{DNA Extraction and PCR Assay}

The DNA extraction was carried out by the boiling method as explained by Perez-Perez and Hanson (16). Six families of plasmid-mediated AmpC betalactamases, including DHA, MOX, ACC, EBC, CIT and FOX were amplified by a polymerase chain reaction (PCR) using the primers shown in Table 1. PCR reaction $(50 \mu \mathrm{L})$ contained $50 \mathrm{mM} \mathrm{KCl}, 20 \mathrm{mM}$ Tris- $\mathrm{HCl}(\mathrm{pH} 8.4), 1.5 \mathrm{mM} \mathrm{MgCl} 2,0.2 \mathrm{mM}$ each deoxynucleoside triphosphate, $0.5 \mu \mathrm{M}$ of each primers, $100 \mathrm{ng}$ of extracted DNA and 1.25 U of Taq DNA polymerase (Ampliqon, Denmark). PCR reaction was

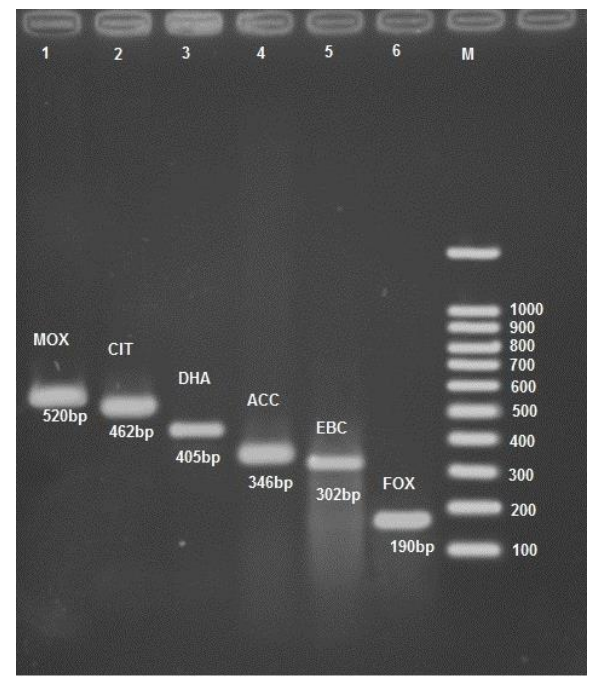

Figure 1. PCR amplification of the $A m p C$ genes. Lane 1-6 positive results for $A m p C$ genes, M: 100 bp DNA ladder.

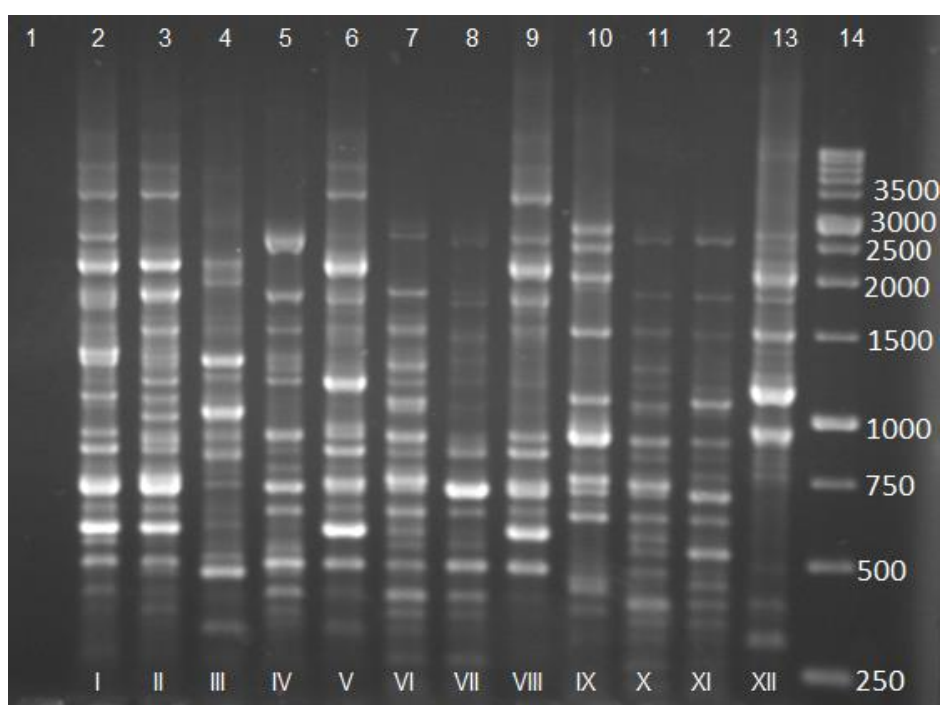

Figure 2. Example of DNA banding patterns obtained for AmpC producing $K$. pneumoniae isolates by ERIC-PCR fingerprinting. 1 : Negative Control, 2-13: Twelve clonal types of $K$. pneumoniae isolates, 14: $1 \mathrm{~Kb}$ Ladder). 


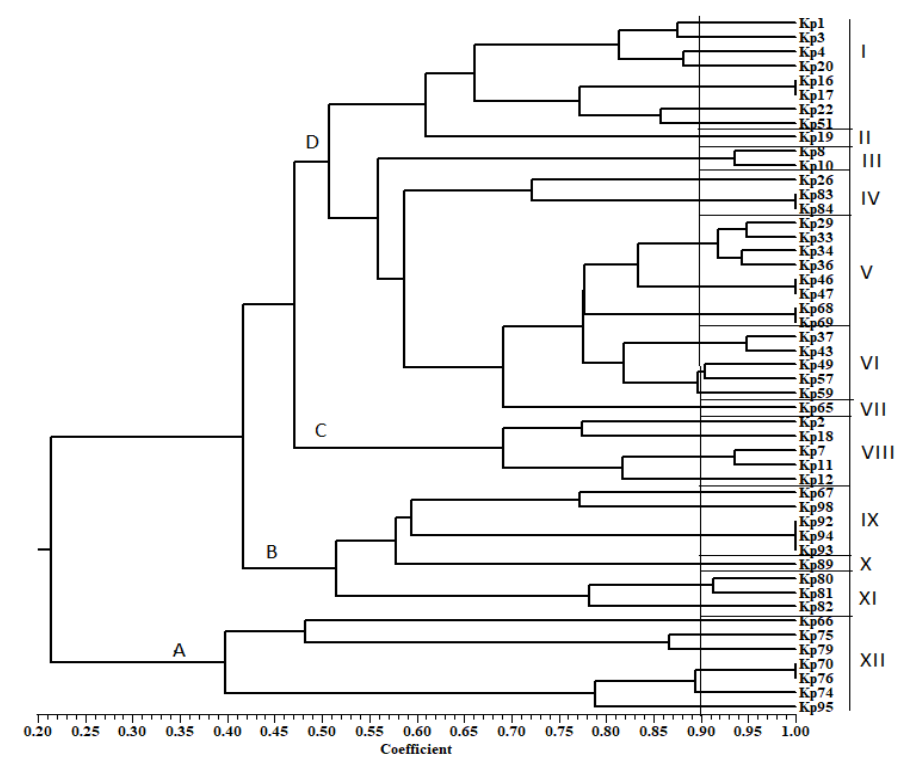

Figure 3. Dendrogram generated by NTSYS software of ERIC-PCR patterns from the 49 AmpC producing isolates. The vertical line represents the similarity cut-off level of $90 \%$.

carried out as follows: initial denaturation at $94^{\circ} \mathrm{C}$ for $3 \mathrm{~min}$ followed by denaturation at $94^{\circ} \mathrm{C}$ for $30 \mathrm{~s}$, annealing at $64^{\circ} \mathrm{C}$ for $30 \mathrm{~s}$, extension at $72^{\circ} \mathrm{C}$ for $1 \mathrm{~min}$ (25 cycles) and a final extension at $72^{\circ} \mathrm{C}$ for $7 \mathrm{~min}$.

\section{Molecular Typing of AmpC-producing Isolates by ERIC-PCR}

The clonal relationships among the AmpCproducing $K$. pnumoniae isolates were determined by ERIC-PCR using the ERIC2 primer as previously described (17).

Briefly, $2 \mu \mathrm{L}$ of the DNA template was added to 12.5 $\mu \mathrm{L}$ master mix (Ampliqon, Denmark), $1 \mu \mathrm{L}$ primer (10 pmol), and $9.5 \mu \mathrm{L} \mathrm{H}_{2} \mathrm{O}$. A PCR reaction was performed under the following conditions: initial denaturation at $94^{\circ} \mathrm{C}$ for $15 \mathrm{~min}$ followed by denaturation at $94^{\circ} \mathrm{C}$ for $1 \mathrm{~min}$, annealing at $37^{\circ} \mathrm{C}$ for $1 \mathrm{~min}$, extension at $72^{\circ} \mathrm{C}$ for $1 \mathrm{~min}$ ( 40 cycles), and a final extension at $72^{\circ} \mathrm{C}$ for $8 \mathrm{~min}$. The resulting products were analyzed on $1.5 \%$ agarose gels. Then, the presence and absence of the bands were scored as 1 and 0 , respectively, and the data were analyzed by the NTSYS program (NTSYSpc version 2.10e). Finally, a cluster analysis was performed, and a dendrogram was constructed using an unweighted pair group method with arithmetic averages (UPGMA). To identify clonally related isolates, the similarity cut-off level was set at $90 \%$ (18).

\section{Statistical Analysis}

Data were analyzed with SPSS 20 (SPSS Inc., Chicago, Ill., USA). Differences between antibiotic resistance among AmpC-positive and negative isolates were statistically analyzed by Chi-square tests. A Pvalue $<0.05$ was considered significant.

\section{Results}

One hundred $K$. pneumoniae isolates were obtained from the urine samples of patients with UTIs at Milad Hospital during the aforementioned study period. Of these, 50 isolates $(50 \%)$ were obtained from females, and $50(50 \%)$ were obtained from males. The mean age of patients was $46.95 \pm 23$ years. The highest rates of resistance were observed against amikacin and levofloxacin (65\% and 64\%, respectively). Moreover, the highest susceptibility was demonstrated in relation to aztreonam and imipenem (97\% and $83 \%$, respectively). In this study, more than $50 \%$ of the isolates were resistant to gentimicin, cefepime, ceftazidime, and piperacillin. Among the $100 \mathrm{~K}$. pneumoniae isolates, 49 (49\%) produced AmpC betalactamases. The results of antibiotic susceptibility testing are shown in Table 2.

Among the $100 \mathrm{~K}$. pneumoniae isolates studied, the PCR revealed that PMABL genes were present in 49 (49\%) isolates. Of these, 34 isolates harbored only one $A m p C$ gene group, including $\operatorname{MOX}(\mathrm{n}=11), \operatorname{EBC}(\mathrm{n}=8)$, $\operatorname{ACC}(n=7), \operatorname{CIT}(n=4)$, FOX $(n=2)$, and DHA $(n=2)$. The 15 remaining PMABL-containing isolates harbored at least two $A m p C$ gene groups as follows: DHA, CIT, and MOX in 1 isolate; CIT and MOX in 2 isolates; CIT and ACC in 2 isolates; MOX and ACC in 2 isolates; FOX and DHA in 1 isolate; DHA and ACC in 2 isolates; DHA and MOX in 2 isolates; DHA and CIT in 2 isolates; and EBC and ACC in 1 isolate. Figure 1 displays the electrophoretic pattern of the AmpC genes.

The antimicrobial susceptibility pattern of the 49 AmpC-producers showed resistance levels of $49 \%$ 
$(n=24)$ to piperacillin and gentamicin, $69.4 \%(n=34)$ to amikacin, $63.3 \%(n=31)$ to levofloxacin, $44.9 \%(n=22)$ to ciprofloxacin, $55 \%(\mathrm{n}=27)$ to ceftazidime, $46.9 \%$ $(n=23)$ to cefepime, $38.8 \% \quad(n=19)$ to ceftriaxone, $28.6 \%(n=14)$ to meropenem, and $10.2 \%(n=5)$ to imipenem. There was a significant association $(P<0.05)$ between $A m p C$ gene carriage and resistance to cefoxitin and levofloxacin. In this study, aztreonam (98\% susceptibility) was found to be the most active antibiotic against AmpC-producing isolates.

Multidrug drug resistance was detected in 30 (61.2\%) of the AmpC beta-lactamase producers. These isolates were distributed into 24 antimicrobial resistance patterns, dominated by resistance to gentamicin/amikacin/meropenem/ceftriaxone/cefoxiti n (GM/AK/MER/CRO/FOX; 3/30, 10\%), followed by amikacin/cefepime/ceftazidime/ciprofloxacin/levoflox acin/piperacillin (AK/CPM/CZA/CIP/LEV/PRL; 2/30, $6.7 \%)$. The profile of antimicrobial sensitivity in MDR isolates and the prevalence of $A m p C$ beta-lactamase genes are reported in Table 3.

Enterobacterial repetitive intergenic consensus analyses revealed 12 distinct patterns of AmpCproducing $K$. pneumoniae isolates with a similarity of above $90 \%$ (Figures 2 and 3 ). The 49 AmpC-producing isolates were divided into four groups $(\mathrm{A}, \mathrm{B}, \mathrm{C}$, and $\mathrm{D})$, among which group $\mathrm{D}$, with 7 clonal types and 28 isolates, was the most dominant. As shown in the dendrogram, among 12 clonal types, types I, V, and XII were the predominant types, with 8,8 , and 7 isolates, respectively (Figure 3).

Table 1. List of used primers in the present study.

\begin{tabular}{|c|c|c|c|c|}
\hline Primer & Oligonucleotide sequence ( $5^{\prime}$ to $\left.3^{\prime}\right)$ & Target genes & $\begin{array}{l}\text { Fragment } \\
\text { length (bp) }\end{array}$ & $\begin{array}{c}\text { Referenc } \\
\text { e }\end{array}$ \\
\hline MOXMF & F: GCTGCTCAAGGAGCACAGGAT & \multirow{2}{*}{$\begin{array}{c}\text { MOX-1, MOX-2, } \\
\text { CMY-1, } \\
\text { CMY-8 to CMY-11 }\end{array}$} & \multirow{2}{*}{520} & \multirow{2}{*}{16} \\
\hline MOXMR & R: CACATTGACATAGGTGTGGTGC & & & \\
\hline CITMF & F: TGGCCAGAACTGACAGGCAAA & \multirow{2}{*}{$\begin{array}{l}\text { LAT-1 to LAT-4, } \\
\text { CMY-2 } \\
\text { to CMY-7, BIL-1 }\end{array}$} & \multirow{2}{*}{462} & \multirow{2}{*}{16} \\
\hline CITMR & R: TTTCTCCTGAACGTGGCTGGC & & & \\
\hline DHAMF & F: AACTTTCACAGGTGTGCTGGGT & \multirow{2}{*}{ DHA-1, DHA-2 } & \multirow{2}{*}{405} & \multirow{2}{*}{16} \\
\hline DHAMR & R: CCGTACGCATACTGGCTTTGC & & & \\
\hline ACCMF & F: AACAGCCTCAGCAGCCGGTTA & \multirow{2}{*}{ ACC } & \multirow{2}{*}{346} & \multirow{2}{*}{16} \\
\hline ACCMR & R: TTCGCCGCAATCATCCCTAGC & & & \\
\hline EBCMF & F: TCGGTAAAGCCGATGTTGCGG & \multirow{2}{*}{ MIR-1T ACT-1 } & \multirow{2}{*}{302} & \multirow{2}{*}{16} \\
\hline EBCMR & R: CTTCCACTGCGGCTGCCAGTT & & & \\
\hline FOXMF & F: AACATGGGGTATCAGGGAGATG & \multirow{3}{*}{ FOX-1 to FOX-5b } & \multirow{3}{*}{190} & \multirow{2}{*}{16} \\
\hline FOXMR & R: CAAAGCGCGTAACCGGATTGG & & & \\
\hline ERIC-2 & AAGTAAGTGACTGGGGTGAGCG & & & 17 \\
\hline
\end{tabular}

Table 2. Antimicrobial susceptibilities of the $K$. pneumoniae isolates $(n=100)$.

\begin{tabular}{cccc} 
Antimicrobial agents & Susceptible, No. $(\%)$ & Resistant, No. (\%) & Intermediate, No. $(\%)$ \\
\hline Gentamicin & $44(44 \%)$ & $52(52 \%)$ & $4(4 \%)$ \\
\hline Amikacin & $29(29 \%)$ & $65(65 \%)$ & $6(6 \%)$ \\
\hline Imipenem & $83(83 \%)$ & $11(11 \%)$ & $6(6 \%)$ \\
Meropenem & $59(59 \%)$ & $35(35 \%)$ & $6(6 \%)$ \\
\hline
\end{tabular}




$\begin{array}{cccc}\text { Antimicrobial agents } & \text { Susceptible, No. }(\%) & \text { Resistant, No. }(\%) & \text { Intermediate, No. }(\%) \\ \text { Ciprofloxacin } & 27(27 \%) & 47(47 \%) & 17(17 \%) \\ \text { Levofloxacin } & 31(31 \%) & 64(64 \%) & 5(5 \%) \\ \text { Aztreonam } & 97(97 \%) & 0(0 \%) & 3(3 \%) \\ \text { Cefepime } & 36(36 \%) & 57(57 \%) & 7(7 \%) \\ \text { Ceftazidime } & 41(41 \%) & 54(54 \%) & 3(3 \%) \\ \text { Cefoxitin } & 65(65 \%) & 31(31 \%) & 2(2 \%) \\ \text { Ceftriaxone } & 67(67 \%) & 55(55 \%) & 4(4 \%) \\ \text { Piperacillin } & 41(41 \%) & 32 \%) & 5(5 \%)\end{array}$

Table 3. Antimicrobial resistance patterns of multidrug resistant $K$. pneumoniae isolates and frequency of genes coding for MDR AmpC beta-lactamase.

\begin{tabular}{|c|c|c|}
\hline Strain & Antimicrobial Resistance profile & AmpC groups \\
\hline Kp2 & GM-MEP$^{\Delta}$-CPM-CZA-CIP-LEV & EBC \\
\hline Kp4 & GM-AK-MEM-CPM-CZA-CIP- LEV-PPL-CRO & CIT \\
\hline Kp7 & AK-CPM-CZA-LEV-CRO-FOX & CIT, MOX \\
\hline Kp8 & GM-AK-MEM ${ }^{\Delta}-\mathrm{CPM}-\mathrm{CZA}-\mathrm{LEV}-\mathrm{PRL}^{\Delta}$ & CIT, ACC \\
\hline Kp10 & GM-CPM-CZA-CIP-LEV-PRL & CIT, MOX \\
\hline Kp11 & GM-AK-IMI-MER-CPM-CZA-CIP-LEV-PRL-CRO-FOX & ACC \\
\hline Kp12 & GM-AK-MER-CPM-CZA-CIP-LEV-PRL & CIT, ACC \\
\hline Kp17 & GM-AK-IMI ${ }^{\Delta}-\mathrm{CPM}^{\Delta}$-CZA-CIP-LEV-FOX & CIT, \\
\hline Kp19 & GM-CPM-CZA-CIP-PRL-CRO-FOX & EBC \\
\hline Kp20 & GM-AK- CPM-CZA-CIP-LEV-PRL & ACC \\
\hline Kp29 & GM-AK-MER $^{\Delta}$-CPM-CZA-LEV-PRL & MOX, ACC \\
\hline Kp33 & GM-AK-IMI-MER-CPM-CZA-CIP-LEV-PRL & MOX \\
\hline Kp34 & GM-AK-CPM ${ }^{\Delta}$-CZA-CIP-LEV-PRL-CRO & MOX \\
\hline Kp46 & GM-AK-IMI-CPM-CZA-CIP-LEV-PRL & MOX \\
\hline Kp49 & AK-MER-CPM-CZA-LEV-PRL-CRO-FOX & ACC \\
\hline Kp51 & AK-CPM-CZA- LEV-PRL-CRO-FOX & FOX \\
\hline Kp57 & AK-CPM ${ }^{\Delta}$-CIP-LEV-PRL-CRO-FOX & ACC \\
\hline Kp68 & AK-IMI-CPM-CZA-LEV-PRL & DHA, ACC \\
\hline Kp75 & GM-MER $^{\Delta}$-CPM-CZA-CIP-LEV-PRL & MOX \\
\hline Kp76 & AK-CPM-CZA-CIP-LEV-PRL & ACC \\
\hline Kp79 & AK-CPM-CZA-CIP-LEV-PRL & FOX \\
\hline Kp81 & AK-CPM-CZA-CIP-LEV-PRL & EBC \\
\hline Kp82 & GM-AK-MER-CRO-FOX & MOX \\
\hline Kp83 & GM-AK-MER-CRO-FOX & MOX \\
\hline Kp89 & GM-AK-CPM-CZA-CIP-PRL-CRO-FOX ${ }^{\Delta}$ & DHA, CIT \\
\hline Kp92 & AK-MER-CPM-CZA-CIP-LEV-PRL & DHA, MOX \\
\hline Kp93 & AK-CPM-CZA-CIP-PRL & MOX \\
\hline Kp94 & GM-AK-CIP-LEV-CRO-FOX & $\mathrm{EBC}, \mathrm{ACC}$ \\
\hline Kp95 & GM-AK-CPM-CZA-CIP-LEV-PRL-FOX & MOX \\
\hline Kp98 & GM-AK-MER-CPM-CZA-CIP ${ }^{\Delta}$-LEV-PRL & CIT \\
\hline
\end{tabular}

Abbreviations: CAZ: Ceftazidime; CRO: Ceftriaxone; IMI: Imipenem; MEM: Meropenem; AK: Amikacin; GM: Gentamicin; CPM: Cefepime; LEV: Levofloxacin; CIP: Ciprofloxacin; PRL: Piperacillin; FOX: Cefoxitin; $\Delta$ Intermediate sensitivity. 


\section{Discussion}

The resistance of $K$. pneumoniae to third- and fourthgeneration cephalosporins due to PMABLs has become a global health threat. The unnecessary or inappropriate use of antibiotics particularly beta-lactams and longterm hospitalization are two possible important causes of the isolation of cephalosporinase-producing $K$. pneumoniae strains in patients. An awareness of the prevalence of PMABLs will be beneficial in terms of epidemiological studies and infection control, as these genes can be transmitted to other microorganisms in hospital settings (19).

Plasmids containing $A m p C$ beta-lactamase genes often carry genes that are resistant to other classes of antimicrobial agents (5). Our results showed that AmpC-producing $K$. pneumoniae isolates were resistant to third- and fourth-generation cephalosporins, including ceftazidime, ceftriaxone, and cefepime. The latter is generally used to treat infections caused by AmpC-producing bacteria because it can pass through the outer membrane rapidly (20). However, in the present study, AmpC-producing $K$. pnumoniae isolates were found to be highly resistant to cefepime (46.9\%). These isolates were also found to be highly resistant to aminoglycoside and quinolone antibiotics, including amikacin, gentamicin, ciprofloxacin, and levofloxacin. Carbapenems are usually prescribed to treat AmpC-producing bacteria (5). However, we found a notable rate of carbapenem resistance among $K$. pneumoniae isolates.

The present study revealed a high frequency of AmpC beta-lactamase among clinical isolates of $K$. pneumoniae (49\%). In a study conducted by Azimi et al. (2013) in Iran, the prevalence of AmpC betalactamase among clinical isolates of $K$. pneumoniae was reported to be $1.6 \%$ (21). In 2014, this value increased to $19 \%$ (7). Our data highlight the sharp rise in AmpC beta-lactamase incidences over the past five years.

The prevalence of $A m p C$ genes observed in this study is higher than in reports from other countries. In Pakistan, Shafiq et al. found that the rate of AmpCproducing K. pneuminiae was $12 \%$ (22). In China, the positive rate of plasmid-mediated AmpCbeta-lactamase-producing $K$. pneumoniae was $10.8 \%$ (8). In India, 32 out of 109 (29.4\%) K. pneumoniae were AmpC-positive (23). However, a higher prevalence of $A m p C$ beta-lactamase genes (77\%) was reported in Korea (24). The primary reasons for the high occurrence of PMABL in Iran may be due to the relatively high rates of self-medication and the indiscriminate consumption of extended-spectrum cephalosporins in hospitals.

Japoni-Nejad et al. showed that, among 100 clinical isolates of K. pneumoniae, 19 isolates harbored AmpC genes that belong to CIT (42.2\%), MOX (36.8\%), EBC $(15.7 \%)$, and DHA (5.2\%) cluster genes (7). Ghanavati et al. (2016) discovered that $43.1 \%$ of $K$. pneumoniae isolates from burn patients in Iran harbor AmpC genes. Of these cases, $22.5 \%$ of the isolates carried the CIT gene, and $21.5 \%$ carried the $E B C$ gene, whereas only $9.8 \%$ and $7.8 \%$ carried FOX and DHA genes, respectively (25). According to our data, the most prevalent AmpC genes among K. pneumoniae isolates resulting from UTIs are MOX and ACC. This is the first study to describe the presence of the ACC gene cluster in K. pneumoniae isolates in Iran.

In the present study, ERIC-PCR typing revealed the polyclonal distribution of AmpC-producing $K$. pneumoniae isolates (Figure 2). The genetic heterogeneity among the isolates revealed that different subtypes of $K$. pneumoniae were involved in UTIs in patients at Milad Hospital. Our findings are consistent with those reported by Seifi et al. (2).

In a study conducted by Ghasemian et al. in Tehran, a wide genetic diversity of $K$. pneumoniae isolates was reported (26). Likewise, results from studies conducted in other countries revealed the genetic diversity of clinical isolates of K. pneumoniae (27-29).

In our study, there was no relationship between ERIC type and antibiotic resistance patterns. In other words, strains of a specific ERIC type showed different antibiotic patterns. These results are in agreement with the findings of previous studies $(29,30)$.

\section{Conclusion}

The present study revealed a high frequency of PMABL-producing MDR $K$. pnuemoniae isolates in UTI patients at Milad Hospital. It also indicated the coexistence of $A m p C$ cluster genes in some isolates. This is the first study to describe the presence of the $A C C$ cluster gene in $K$. pnuemoniae isolates in Iran. The emergence of the polyclonal MDR and blaAmpCgene-carrying $K$. pnuemoniae isolates indicate that surveillance policies are needed for the detection and control of the dissemination of such organisms.

\section{Acknowledgement}

This research is derived from the MSc thesis supported by Islamic Azad University, Islamshahr branch.

\section{Conflict of Interest}

Authors declared no conflict of interests.

\section{References}

1. Bhandari R, Pant ND, Poudel A, Sharma M. Assessment of the effectiveness of three different cephalosporin/clavulanate combinations for the phenotypic confirmation of extended-spectrum betalactamase producing bacteria isolated from urine samples at National Public Health Laboratory, 
Kathmandu, Nepal. BMC Res Notes. 2016;9:390. [DOI:10.1186/s13104-016-2192-2]

2. Seifi K, Kazemian H, Heidari H, et al. Evaluation of biofilm formation among Klebsiella pneumoniae isolates and molecular characterization by ERIC-PCR. Jundishapur J Microbiol. 2016;9(1):e30682. [DOI:10.5812/jjm.30682]

3. Netikul T., Kiratisin P. Genetic characterization of carbapenem resistant Enterobacteriaceae and the spread of carbapenem resistant Klebsiella pneumonia ST340 at a university hospital in Thailand. PLoS One. 2015;10(9):e0139116.

[DOI:10.1371/journal.pone.0139116]

4. Lampri N, Galani I, Poulakou G, et al. Mecillinam/clavulanate combination: a possible option for the treatment of community-acquired uncomplicated urinary tract infections caused by extended-spectrum blactamase-producing Escherichia coli. J Antimicrob Chemother. 2012;67(10):2424-8. [DOI:10.1093/jac/dks215]

5. Jacoby GA. AmpC b-lactamases. Clin Microbiol Rev. 2009; 22(1): 161-82. [DOI:10.1128/CMR.00036-08]

6. Bauernfeind A, Chong Y, Schweighart Y: Extended broad spectrum -lactamase in Klebsiella pneumoniae including resistance to cephamycins. Infection. 1989; 17(5): 316-21. [DOI:10.1007/BF01650718]

7. Japoni-Nejad A, Ghaznavi-Rad E., van Belkum A. Characterization of plasmid-mediated AmpC and carbapenemases among Iranain nosocomial isolates of Klebsiella pneumoniae using phenotyping and genotyping methods. Osong Public Health Res Perspect. 2014; 53(6): 333-38. [DOI:10.1016/j.phrp.2014.09.003]

8. Liu XQ, Liu YR. Detection and genotype analysis of AmpC $\beta$-lactamase in Klebsiella pneumoniae from tertiary hospitals. Exp Ther Med. 2016; 12(1):480-84. [DOI:10.3892/etm.2016.3295]

9. Pitout JD, Le PG, Moore KL, Church DL, Gregson DB. Detection of AmpC beta-lactamases in Escherichia coli, Klebsiella spp., Salmonella spp. and Proteus mirabilis in a regional clinical microbiology laboratory. Clin Microbiol Infect. 2010; 16(2): 165-70. [DOI:10.1111/j.1469-0691.2009.02756.x]

10. Livermore DM. Current epidemiology and growing resistance of gram-negative pathogens. Korean J Internal Med. 2012; 27(2): 128-42. [DOI:10.3904/kjim.2012.27.2.128]

11. Maina D, Revathi G, Kariuki S, Ozwara H. Genotypes and cephalosporin susceptibility in extended-spectrum beta-lactamase producing Enterobacteriaceae in the community. J Infect Dev Ctries. 2012; 6(6): 470-77. [DOI:10.3855/jidc.1456]

12. Cheesbrough M. District laboratory practice in tropical countries, part II. 2nd ed. Cambridge University Press; 2006.

13. CLSI. Performance Standards for Antimicrobial Susceptibility Testing. 27th ed. CLSI supplement M100. Wayne, PA: Clinical and Laboratory Standards Institute; 2017
14. Magiorakos AP, Srinivasan A, Carey RB, et al. Multidrug-resistant, extensively drug-resistant and pan drug-resistant bacteria: an international expert proposal for interim standard definitions for acquired resistance. Clin Microbiol Infect. 2012; 18:268-81. [DOI:10.1111/j.1469-0691.2011.03570.x]

15. Lee W, Jung B, Hong SG, et al. Comparison of 3 phenotypicdetection methods for identifying plasmidmediated AmpC betalactamase-producing Escherichia coli, Klebsiella pneumoniae, and Proteus mirabilis strains. Korean J Lab Med. 2009; 29(5): 448-54. [DOI:10.3343/kjlm.2009.29.5.448]

16. Perez-Perez FJ, Hanson ND. Detection of plasmidmediated AmpC b-lactamase genes in clinical isolates by using multiplex PCR. J Clin Microbiol. 2002; 40(6): 2153-162. [DOI:10.1128/JCM.40.6.2153-2162.2002]

17. Wasfi R, Elkhatib WF, Ashour HM. Molecular typing and virulence analysis of multidrug resistant Klebsiella pneumoniae clinical isolates recovered from Egyptian hospitals. Sci Rep 2016.;6:38929. [DOI:10.1038/srep38929]

18. Dalmolin TV, Bianchini BV, Rossi GG, et al. Detection and analysis of different interactions between resistance mechanisms and carbapenems in clinical isolates of Klebsiella pneumoniae. Braz J Microbiol. 2017; 48(3): 493-98. [DOI:10.1016/j.bjm.2017.01.003]

19. Peirano G: Multi resistant Enterobacteriaceae new threat to an old problem; expect review of anti infective therapy. Expert Rev Anti Infect Ther. 2008; 6(5): 65769. [DOI:10.1586/14787210.6.5.657]

20. Shi WF, Zhou J, Qin JP. Transconjugation and geno-typing of the plasmid mediated AmpC beta lactamase and extended spectrum beta lactamase genes in Klebsiella pneumoniae. Chin Med J (Engl). 2009; 122: 1092-96.

21. Azimi L, Erajiyan G, Talebi M, et al. Phenotypic and molecular characterization of plasmid mediated AmpC among clinical isolates of Klebsiella pneumoniae isolated from different hospitals in Tehran. J Clin Diagn Res. 2015;9(4):DC01-3. [DOI:10.7860/JCDR/2014/11037.5797]

22. Shafiq M, Rahman H, Qasim M, et al. Prevalence of plasmid-mediated AmpC $\beta$-lactamases in Escherichia coli and Klebsiella pneumoniae at tertiary care hospital of Islamabad, Pakistan. Eur J Microbiol Immunol. 2013;(3): 267-71. [DOI:10.1556/EuJMI.3.2013.4.5]

23. Mohamudha PR, Harish BN, Parija SC. Molecular description of plasmid-mediated AmpC $\beta$-lactamases among nosocomial isolates of Escherichia coli \& Klebsiella pneumoniae from six different hospitals in India. Indian J Med Res. 2012; 135(1): 114-19. [DOI:10.4103/0971-5916.93433]

24. Lee K, Lee M, Shin JH, et al. Prevalence of plasmidmediated AmpC beta-lactamases in Escherichia coli and Klebsiella pneumoniae in Korea. Microb Drug Resist. 2006; 12(1): 44-49. [DOI:10.1089/mdr.2006.12.44]

25. Ghanavati R, Darban-Sarokhalil D, Navab-Moghadam F, Kazemian H, Irajian G, Razavi S. First report of coexistence of AmpC beta-lactamase genes in Klebsiella pneumoniae strains isolated from burn 
patients. Acta Microbiol Immunol Hung. 2017; 64(4): 455-62. [DOI:10.1556/030.64.2017.028]

26. Ghasemian A, Shafiei M, Eslami M, Vafaei M, Nojoom F, Rajabi-Vardanjani H. Molecular typing of Klebsiella pneumoniae isolates using repetitive extragenic palindromic sequence-based PCR in a hospital in Tehran, Iran. Int J Enteric Pathog. 2018; 6(1): 27-30. [DOI:10.15171/ijep.2018.07]

27. Cabral AB, Melo Rde C, Maciel MA, Lopes AC. Multidrug resistance genes, including bla (KPC) and bla (CTX)-M-2, among Klebsiella pneumoniae isolated in Recife, Brazil. Rev Soc Bras Med Trop. 2012; 45(5): 572-78. [DOI:10.1590/S0037-86822012000500007]

28. Yan JJ, Hsueh PR, Lu JJ, et al. Extended-spectrum $\beta$ lactamases and plasmid-mediated AmpC enzymes among clinical isolates of Escherichia coli and
Klebsiella pneumoniae from seven medical centers in Taiwan. Antimicrob Agents Chemother. 2006; 50(5): 1861-64. [DOI:10.1128/AAC.50.5.1861-1864.2006]

29. Jena J, Debata NK, Sahoo RK, Gaur M, Subudhi E. Genetic diversity study of various $\beta$-lactamaseproducing multidrug-resistant Escherichia coli isolates from a tertiary care hospital using ERIC-PCR. Indian J Med Res. 2017;146 (Supplement):S23-S29. [DOI:10.4103/ijmr.IJMR_575_16]

30. Lim KT, Yeo CC, Yasin RM, Balan G, Thong KL. Characterization of multidrug-resistant and extendedspectrum b-lactamase-producing Klebsiella pneumoniae strains from Malaysian hospitals. J Med Microbiol. 2009; 58: 1463-69. [DOI:10.1099/jmm.0.011114-0]

\section{Download citation:}

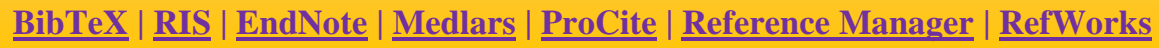

Send citation to:

(8. Mendeley 2 Zotero (i) RefWorks RefWorks 